\title{
A HISTÓRIA EM QUADRINHOS COMO RECURSO DIDÁTICO-PEDAGÓGICO PARA A EDUCAÇÃO AMBIENTAL: "O AQUECIMENTO GLOBAL"
}

\section{THE COMIC AS PEDAGOGIC-DIDACTIC RESOURCE FOR ENVIRONMENTAL EDUCATION: "GLOBAL WARMING"}

\section{Wilson Ricardo Antoniassi de Almeida ${ }^{1}$, Vanessa de Souza Moreno $^{2}$, Sâmia Maria Tauk-Tornisielo ${ }^{3}$, Newton La Scala Júnior ${ }^{4}$}

\author{
${ }^{1,2,3}$ Centro de Estudos Ambientais, UNESP, Campus Rio Claro, e-mail: \\ ricantoniassi@hotmail.com \\ ${ }^{4}$ Faculdade de Ciências Agrárias e Veterinárias - FCAV, UNESP, Campus \\ Jaboticabal, e-mail: lascala@fcav.unesp.br
}

\begin{abstract}
RESUMO
Com a constatação de que a influência das ações antrópicas tem ocasionado consequências nocivas ao ambiente, iniciou-se uma série de compromissos mundiais, intergovernamentais e interinstitucionais, a fim de minimizar esses impactos ambientais. Uma das propostas estabelecidas nesses compromissos refere-se à educação ambiental, já que esta permite que o indivíduo e a coletividade se conscientizem e construam valores sociais, conhecimentos, atitudes e mudanças de hábitos, visando interagir de forma sustentável com o ambiente. Nesta perspectiva, este estudo focado em jovens do Ensino Médio teve como objetivos verificar os hábitos de leitura e os gêneros preferidos, bem como a presença ou ausência de conceitos, além de analisar os erros conceituais cometidos pelos mesmos, relativos à temática do "aquecimento global". A partir destas observações, pretendeu-se produzir uma história em quadrinhos referente ao tema "aquecimento global", focalizando os processos e técnicas relativas à mitigação de seus impactos, propondo, desta forma, oferecer um recurso didático-pedagógico lúdico, atrativo e divertido, podendo tornar-se uma ferramenta eficiente para o processo de educação ambiental, na expectativa de que este venha influenciar de forma positiva a leitura e a aprendizagem desses indivíduos.
\end{abstract}

Palavras-chave: Ambiente. Sustentabilidade. Qualidade de vida. Recurso didático-pedagógico.

\footnotetext{
ABSTRACT

The influence of human activities has caused harmful consequences to the environment, began a series of intergovernmental and inter-global commitments to minimize these environmental impacts. One of the proposals set forth in those commitments refers to environmental education, as this allows the individual and the community are aware and build social value's, knowledge, attitudes and changes in habits, in order to interact sustainably with the environment. In this perspective, this study focused on young high school students aimed at investigating the reading
} 
habits of the favorites genres, as well as the presence or absence of concepts, and analyze the conceptual mistakes committed by them, on the theme of "global warming". From these observations, it sought to produce a comic for the theme of "global warming", focusing on the processes and techniques for mitigating its impacts, offering thus provide a teaching resource teaching-play, attractive and fun and can become an efficient tool for the environmental education process in the hope that it will positively influence reading and learning these subjects.

Keywords: Environment. Sustainability. Quality of life. Pedagogical-didactic resource.

\section{INTRODUÇÃO}

A origem das histórias em quadrinhos apresenta características diferentes da sua origem. Ao contrário das primeiras histórias européias, que apareceram em álbuns e folhas volantes com uma pequena tiragem e só posteriormente publicadas em periódicos, os quadrinhos americanos foram desde o início publicados em suplementos dominicais de jornais com tiragens muito elevadas. Também, ao contrário das histórias européias, desde o início destinadas às crianças, as americanas eram destinadas ao público adulto e, por serem editadas em jornais, apresentavam qualidade técnica inferior (FERRO, 1987).

Com o crescimento do conhecimento das questões ambientais e as interações de suas conseqüências entre as nações, suas discussões passaram a ter uma relevância internacional (BRASIL, 1998a). A partir dessa constatação, iniciou-se o processo de compromissos mundiais intergovernamentais e interinstitucionais acerca da minimização dos impactos ambientais causados pela ocupação humana sobre o ambiente (ARAÚJO, 2002).

No Brasil, essa preocupação está evidente no artigo 225 da Constituição Federal (BRASIL, 1988), estabelecendo que "todos têm direito ao meio ambiente ecologicamente equilibrado, bem de uso comum do povo e essencial à sadia qualidade de vida, impondo-se ao poder público e à coletividade o dever de defendê-lo e preservá-lo para presentes e futuras gerações". O parágrafo $1^{\circ}$ (inciso VI) desse mesmo artigo determina que, para assegurar a efetivação desse direito, incumbe ao poder público, dentre várias providências, promover a educação ambiental (EA) em todos os níveis de ensino e conscientizar a população da importância da preservação do ambiente. A EA está direcionada para propostas pedagógicas focalizadas na conscientização, mudança de comportamento, desenvolvimento de competências, capacidade de avaliação e participação dos educandos (REIGOTA, 1998).

O tema ambiente foi inserido como um dos temas transversais (BRASIL, 1998b), por se tratar de questões importantes, urgentes e presentes sob várias formas na vida cotidiana, já que o futuro da humanidade depende da relação estabelecida entre a natureza e o uso de recursos naturais disponíveis,

Diante dessa perspectiva, "é função da escola contribuir para a conscientização dos cidadãos, tornando-os aptos a agir na realidade sócio-ambiental de forma comprometida com a qualidade de vida da sociedade, local e globalmente" (BRASIL, 1998b). Dessa forma, é necessário que a instituição trabalhe não apenas as informações e conceitos, mas também as atitudes, com a formação de valores, além do ensino e aprendizagem de habilidades e procedimentos.

A história em quadrinhos (HQ) pode ser um eficiente recurso para desenvolver os princípios da EA, pois, além de proporcionar uma aprendizagem de forma lúdica, crítica e interativa, pode ser utilizada com finalidades pedagógicas nas mais variadas disciplinas e já ganha espaço em salas de aula e em livros didáticos (VERGUEIRO, 2005; ROCHA, 2008), oferecendo entretenimento, jogo e fantasia, sendo um modo ativo de educar (LUYTEN, 1985; GIESTA, 2002).

Segundo Snyders (1996), quando a realização de atividades se dá com alegria, desperta nos jovens a vontade de aproveitar cada situação de aprendizagem, de aprender novas idéias e de 
desenvolver-se como ser humano. Sendo assim, a HQ poderá ser um instrumento adequado para trabalhar temas que colaborem com a revisão de hábitos no intuito de proporcionar medidas para a conservação do ambiente.

O conteúdo das narrativas de uma HQ geralmente remete a temas universais e valores humanos sempre atuais e esse conhecimento ultrapassa as fronteiras do geral para o que é mais particular e subjetivo. Por isso, os quadrinhos são entendidos por todos, sem que se perca sua essência atemporal (CATONIO e CRUZ, 2008).

As atividades humanas sempre influenciaram o ambiente, porém, após a Revolução Industrial, em meados do século XVIII, os impactos dessas atividades tomaram proporções em escalas globais, principalmente aquelas envolvidas com a queima de combustíveis fósseis para uso industrial e residencial e queima de biomassa (CHANG, 2004).

O tema Aquecimento Global, além de atual é preocupante, já que as conseqüências do efeito estufa ampliado são cada vez mais evidentes e os impactos previstos são alarmantes. Após muitos debates sobre as possíveis causas desse fenômeno, finalmente, a partir de 1990, ficou estabelecida a existência indiscutível de um efeito estufa ampliado, causado por ações antrópicas (IPCC, 1990).

Segundo o UNDP (2006), o aquecimento global poderá promover grandes mudanças na evaporação e na precipitação associadas ao ciclo hidrológico, intensificando enchentes e secas, provocando alterações nas freqüências e intensidade de eventos de temperaturas extremas e na disponibilidade de terras agricultáveis; também são previstos o recuo glacial, a extinção de espécies, o aumento de vetores de doenças e a elevação do nível dos oceanos.

Apesar das evidências acima citadas, é preciso considerar que o efeito estufa é um fenômeno natural, garantido pela presença de gases que ajudam a estabilizar as temperaturas globais em níveis adequados à vida (SARRE, 2000). Existe uma grande confusão no que se refere às características desse fenômeno que, mesmo sendo essencial para a vida, quando ampliado pode ser extremamente prejudicial. Além disso, combater os impactos provocados pelo aquecimento global exige um grande esforço da sociedade, que precisa compreender as bases físicas desse evento para, então, se envolver em um processo de mudanças de hábitos e valores.

A fim de atender aos princípios da sustentabilidade, portanto, o processo de EA deverá buscar transformações nas relações entre os indivíduos, entre estes e a própria sociedade e entre a sociedade e desta com seu próprio ambiente (PHILIPPI JR e MALHEIROS, 2005). Em vista das considerações anteriores, este trabalho teve o objetivo de verificar o nível de conhecimento de alunos de uma $2^{\mathrm{a}}$ série do ensino médio de uma escola pública estadual acerca de questões referentes ao tema aquecimento global, identificando eventuais erros conceituais e atitudinais associados ao mesmo.

Assim, propôs-se, a partir da análise dessas situações, a produção de um gibi sobre essa temática, como um instrumento didático-pedagógico para o processo de educação ambiental, visando proporcionar, por meio de uma linguagem lúdica e com elementos presentes no dia-a-dia, a interação dos estudantes e a compreensão por parte dos mesmos, de conceitos que nem sempre são suficientemente discutidos na escola, como também estimular a conscientização dos alunos e provocar mudanças de hábitos e atitudes que possam contribuir para a mitigação dos impactos ambientais causados pelo aquecimento global.

\section{MATERIAL E MÉTODOS}

\subsection{Aplicação de questionário}

O tema aquecimento global e os conceitos biológicos a ele relacionados - fotossíntese, gases atmosféricos, desmatamento, temperatura ambiental e outros - são devidamente trabalhados no ensino fundamental e médio. No ensino fundamental essa temática é desenvolvida de forma 
indireta, abordando conteúdos básicos como fotossíntese e ciclos biogeoquímicos, enquanto que na segunda série do ensino médio o tratamento do assunto ocorre de forma aplicada, focando a compreensão dos problemas ambientais contemporâneos, como contaminação dos solos e efeito estufa (BRASIL, 1998c; 1998d)

Com o intuito de verificar o nível de conhecimento quanto ao aquecimento global e efeito estufa, foi aplicado um questionário a 35 alunos de segunda série do ensino médio de uma escola pública estadual do município de Limeira, SP., cujas questões nos possibilitariam melhor conhecimento desses educandos. Este nível escolar foi selecionado por que, de acordo com os PCNs (BRASIL, 2000) e a proposta curricular do Estado (SÃO PAULO, 2008a; 2008b), teoricamente, os alunos já teriam aprendido todo o conteúdo necessário para compreender as causas, efeitos e formas de mitigação dos impactos causados pelo aquecimento global.

O questionário foi elaborado de forma que contemplasse aspectos relacionados ao perfil sócio-cultural dos alunos e, também, aqueles relativos ao domínio conceitual, sendo que para este foram elaboradas questões relacionadas ao tema mudanças climáticas globais, com estrutura baseada na linha de raciocínio do último relatório do IPCC (2007). Este último foi dividido em três grupos de estudo: 1) que abordava as bases físicas do efeito estufa; 2) que abordava as conseqüências do aumento do efeito estufa e 3) que abordavam as possibilidades de mitigação dos impactos causados pelo aumento do efeito estufa.

A parte do questionário referente ao perfil sócio-cultural foi composta por sete questões de múltipla escolha e a outra, relacionada ao domínio conceitual continha nove questões, sendo duas dissertativas e sete de múltipla escolha.

\subsection{Elaboração e produção do gibi}

\subsubsection{Definição do conteúdo}

$\mathrm{Na}$ análise das respostas obtidas no questionário foram também verificados eventuais erros conceituais, também permitindo situar o nível de compreensão dos alunos acerca da temática. Baseando-se em consultas aos $\mathrm{PCNs}$, às diretrizes curriculares e à proposta curricular do estado de São Paulo, elencou-se o rol de conteúdos propostos para cada série. A partir deste diagnóstico, foram selecionados os seguintes conteúdos: efeito estufa - características e importância para os seres vivos; atividades antrópicas e efeito estufa ampliado; protocolo de Quioto e mecanismos de desenvolvimento limpo e créditos de carbono. A partir da delimitação dos conteúdos foi realizada uma revisão de literatura específica para cada tema anteriormente citado.

\subsubsection{Definição das características dos personagens}

Foram propostas como características fundamentais para compor os esteriótipos dos personagens, a imaginação e a curiosidade. Desta forma, foram definidos dois protagonistas para a história: uma menina e um menino chamados, respectivamente, Aninha e Pedrinho (FIGURA 1), com idade de 10 anos, período em que os estudantes iniciam o ensino fundamental II, etapa da formação escolar em que tem início o estudo do ambiente e as interferências do homem na natureza (BRASIL, 1998c). No transcurso da redação da história outros personagens coadjuvantes foram sendo criados. 


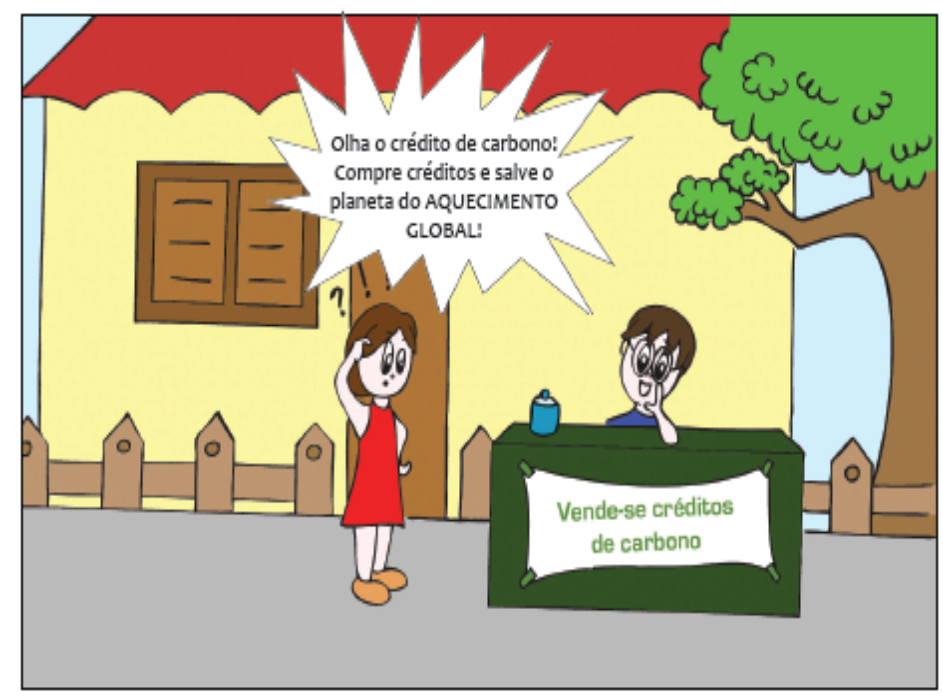

Figura 1. Aninha em frente à casa de Pedrinho que está vendendo créditos de carbono.

\subsubsection{Roteirização}

As HQ apresentam como características um formato de texto peculiar, no qual a narração é feita por meio de seqüências de quadros (vinhetas, imagens, desenhos ou figuras impressos). Os diálogos entre os personagens, seus pensamentos, gritos, sussurros e a própria narração apresentamse na forma de legendas ou inseridas em espaços irregulares delimitados, denominados balões (DINIZ et al., 2006). Para que as ilustrações representassem a história nos quadrinhos, foi necessária a roteirizarão quadro a quadro, nos quais ficam detalhadas as falas e expressões dos personagens, bem como o cenário em que a cena acontece (Figuras 2 e 3). A partir desse detalhamento, a história foi submetida ao processo de ilustração e digitalização.
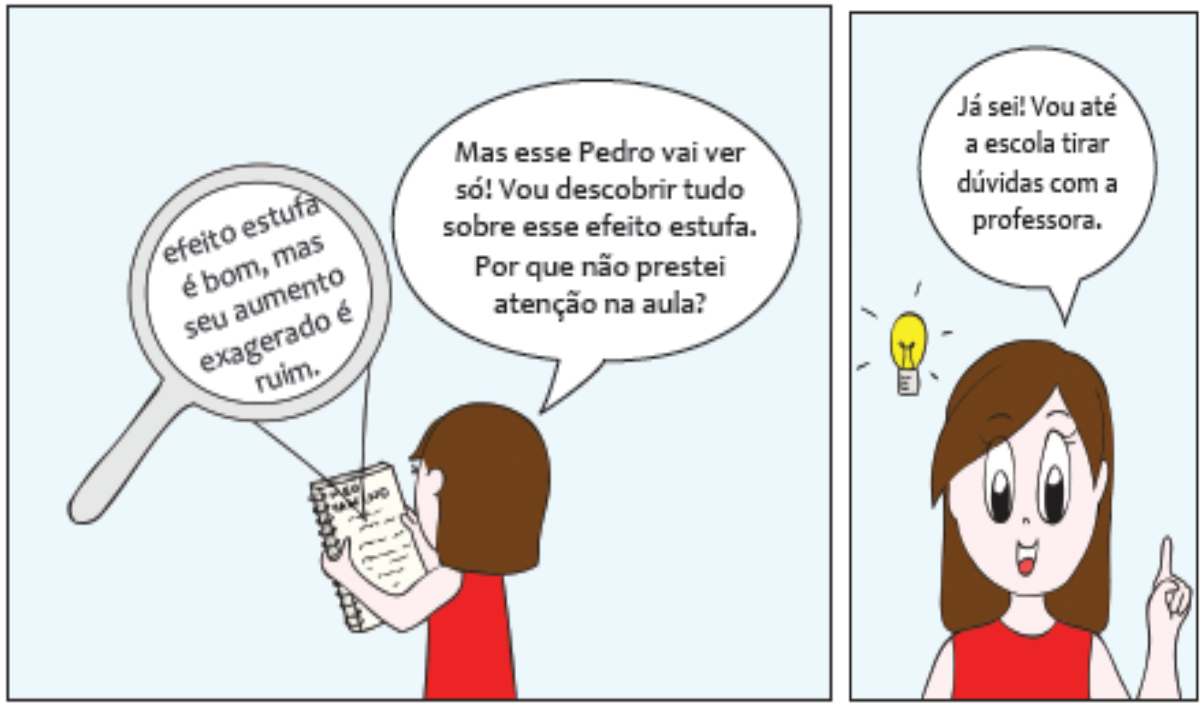

Figura 2. Aninha pesquisando sobre o efeito estufa. 

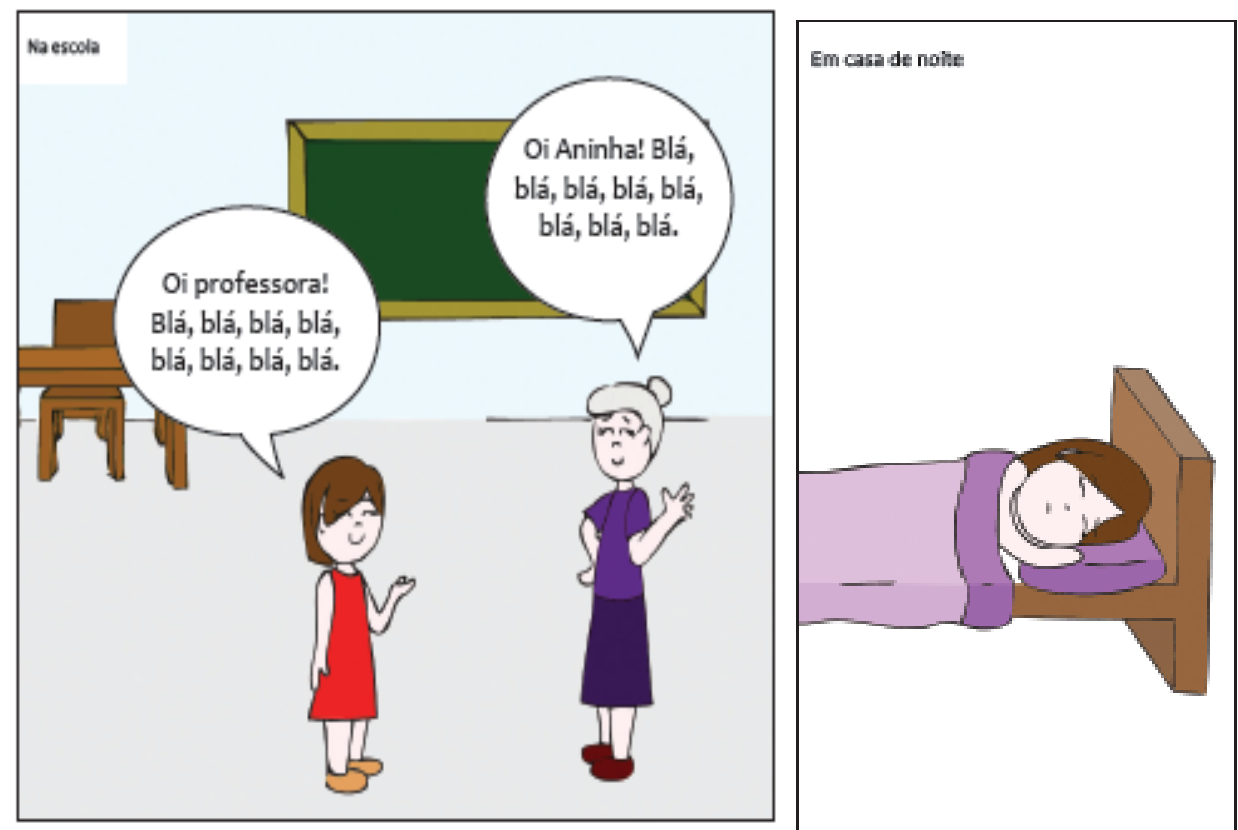

Figura 3. Aninha em busca da compreensão do termo efeito estufa, com sua professora.

\subsubsection{Ilustração}

Inicialmente, as ilustrações foram realizadas manualmente, utilizando-se lápis 6B sobre papel sulfite branco A4 (Figura 4) e depois foram digitalizadas com o uso de um scanner. Para ampliação e remoção de detalhes e coloração foi utilizado o software Adobe Photoshop cs2 (Figura 5) e, ao final, o material foi impresso em papel A4 e devidamente encadernado.
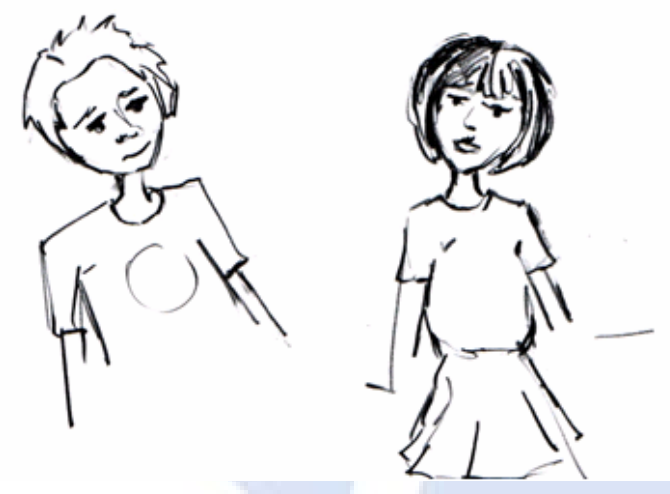

Figura 4. Aninha e Pedrinho. Rascunhos dos primeiros esboços dos personagens. 


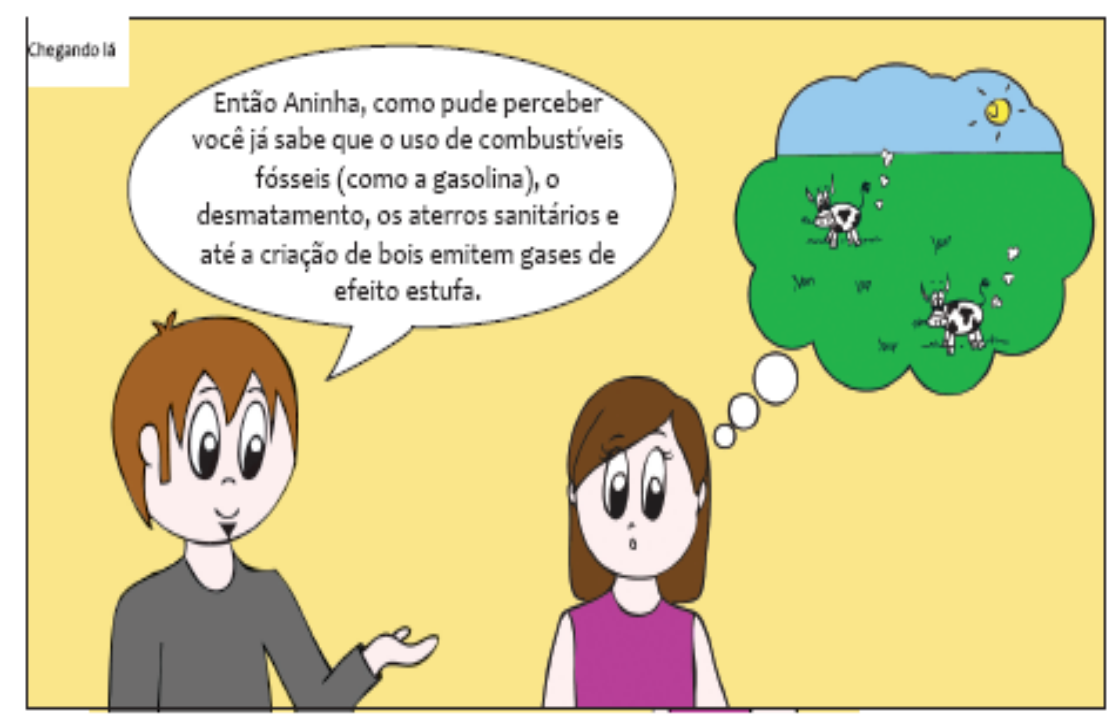

Figura 5. Aninha recebendo orientações e esclarecendo suas dúvidas sobre o efeito estufa.

\section{RESULTADOS E DISCUSSÃO}

\subsection{Questionário}

\subsubsection{Perfil sócio-cultural}

A turma da $2^{\mathrm{a}}$ série do ensino médio objeto desta pesquisa era constituída por 35 alunos e todos responderam ao questionário. Desses alunos, verificou-se que a faixa etária predominante variou entre 16 e 17 anos, representando 33 alunos desse total. Constatou-se grande diversidade no grau de escolaridade dos pais (Tabela 1), sendo que todos apresentavam alguma instrução, pois o item "sem escolaridade" não foi encontrado na amostragem aqui utilizada dos estudantes. Houve a predominância de pais com o ensino fundamental completo e ensino médio completo, sendo apenas três, o número de pais que apresentavam ensino superior completo.

Tabela 1 - Grau de escolaridade dos pais dos alunos que responderam o questionário.

\begin{tabular}{cc}
\hline Níveis de escolaridade & Número de indivíduos \\
\hline Sem escolaridade & 0 \\
Fundamental Incompleto. & 6 \\
Fundamental Completo & 10 \\
Médio Incompleto. & 5 \\
Médio Completo & 9 \\
Superior Incompleto. & 1 \\
Superior Completo & 3 \\
Não soube responder & 1 \\
\hline
\end{tabular}


Em relação aos dados da renda familiar (Tabela 2), observou-se que, assim como para o grau de escolaridade, houve uma distribuição bem variada, concentrada na faixa entre $\mathrm{R} \$ 1.000,00 \mathrm{e}$ $\mathrm{R} \$ 2.000,00$; nenhum aluno possuía renda maior do que $\mathrm{R} \$ 5.000,00$ e 12 alunos apresentavam renda menor do que $\mathrm{R} \$ 1.000,00$, caracterizando o poder aquisitivo do grupo entre médio a baixo.

Tabela 2 - Renda familiar em R\$ (reais) das famílias dos alunos entrevistados.

\begin{tabular}{cc}
\hline Faixas & Número de indivíduos \\
\hline Menor que $\mathrm{R} \$ 1.000,00$ & 12 \\
De $\mathrm{R} \$ 1.000,00$ a $\mathrm{R} \$ 2.000,00$ & 13 \\
De $\mathrm{R} \$ 2.000,00$ a $\mathrm{R} \$ 5.000,00$ & 9 \\
Maior que $\mathrm{R} \$ 5.000,00$ & 0 \\
Não soube responder & 1 \\
\hline
\end{tabular}

Sabe-se que a escolaridade dos pais é considerada o fator de maior importância na determinação do desempenho educacional dos estudantes brasileiros e que dentre todos os determinantes que afetam o nível de escolaridade das pessoas, os recursos familiares são os que aparecem com maior freqüência nos estudos aplicados à realidade brasileira; quanto maior o poder de aquisição das famílias, mais recursos dedicam ao investimento em capital educacional (BARROS et al., 2001).

De forma interessante percebeu-se que no grupo de alunos com renda familiar entre $\mathrm{R} \$ 2.000,00$ e $\mathrm{R} \$ 5.000,00$ quatro deles responderam de forma correta, quando questionados sobre se o efeito estufa era ruim, ou seja, emitiram respostas negativas. No grupo de alunos com renda entre $\mathrm{R} \$ 1.000,00$ e $\mathrm{R} \$ 2.000,00$, dois deles também responderam corretamente, o que não aconteceu com os alunos com renda familiar abaixo de $\mathrm{R} \$ 1.000,00$.

Essa tendência também foi observada quando os alunos foram questionados sobre os termos: mercado de crédito de carbono, seqüestro de carbono, protocolo de Quioto e MDL (Mecanismo de Desenvolvimento Limpo). Os alunos com renda familiar entre R $\$ 1.000,00$ e R \$2.000,00 (77,8\%) já tinham ouvido informações sobre o Protocolo de Quioto, enquanto no grupo de menor renda esse percentual foi reduzido $(16,7 \%)$.

Quando questionados sobre qual fator estava mais diretamente relacionado às mudanças climáticas globais, observou-se o inverso para essa relação, ou seja, quanto maior a renda, maior foi o erro, sendo que no grupo de menor renda (abaixo de $\mathrm{R} \$ 1000,00$ ) o erro foi de $16,7 \%$, enquanto que nos grupos de rendas médias (entre $\mathrm{R} \$ 1.000,00$ e $\mathrm{R} \$ 2.000,00$ e de $\mathrm{R} \$ 2.000,00$ e $\mathrm{R} \$ 5.000,00$ ) os erros foram, respectivamente, de 53,5\% e $66,7 \%$.

Os principais meios de comunicação presentes nos domicílios desses alunos eram a televisão e o computador (internet), sendo que mais de $70 \%$ afirmou possuir esses dois equipamentos, evidenciando grande inclusão digital, embora, como já visto (Tabela 2), se tratasse de um grupo com baixo a médio poder aquisitivo.

Quanto ao hábito de leitura, constatou-se que aproximadamente 63\% dos alunos afirmaram gostar de ler e que, entre os diferentes tipos de leitura (Tabela 3), a HQ esteve entre as três opções preferidas, ocupando o $3^{\circ}$ lugar, com preferência de $48,5 \%$ dos alunos, seguindo os sites da internet $(51,4 \%)$ e as revistas $(68,5 \%)$, respectivamente. 
Tabela 3 - Meios de leitura preferidos pelos alunos entrevistados.

\begin{tabular}{cc}
\hline Meios & \% de indivíduos \\
\hline Livros & 40,0 \\
Revistas & 68,5 \\
HQ (gibi) & 48,5 \\
Sites diversos & 51,4 \\
Jornais impressos & 37,1 \\
\hline
\end{tabular}

\subsubsection{Domínio conceitual}

Observou-se que todos os alunos consultados já tinham ouvido sobre o tema mudanças climáticas globais, no entanto, ao serem questionados sobre qual fator estaria diretamente relacionado com esse evento (Tabela 4), apenas $57,1 \%$ se referiram ao efeito estufa e $37,1 \%$ responderam ser a camada de ozônio. Tal resultado evidenciou um erro conceitual importante, já que estes fatores estão diretamente relacionados a dois problemas ambientais diferentes.

O mais preocupante foi à constatação do conceito errôneo que a grande maioria dos adolescentes tinha sobre o efeito estufa, pois $89,2 \%$ acreditavam que se tratava de algo ruim, no entanto, é sabido que este fenômeno é essencial para a manutenção da vida na Terra. $\mathrm{O}$ aumento deste efeito, todavia, pode ser prejudicial para o sistema climático deste planeta.

Tabela 4 - Fatores mais diretamente relacionados a mudanças climáticas globais.

\begin{tabular}{cc}
\hline Fatores & \% de indivíduos \\
\hline Camada de ozônio & 37,1 \\
Efeito estufa & 57,1 \\
Extinção espécies de animais e vegetais & 2,9 \\
Economia mundial & 0 \\
Chuva ácida & 0 \\
Poluição das águas & 2,9 \\
\hline
\end{tabular}

Quanto aos fatores que poderiam aumentar o efeito estufa, os alunos tiveram a liberdade de optar por mais de uma resposta e as três que mostraram maior incidência foram: aumento da emissão de $\mathrm{CO}_{2}(91,4 \%)$; aumento da emissão de $\mathrm{CH}_{4}(60 \%)$ e aumento da emissão de $\mathrm{N}_{2} \mathrm{O}$ $(51,4 \%)$. Outros fatores, como mudanças no uso da terra, chuva ácida e aterros sanitários não contabilizaram nem 50\%, evidenciando que apesar desses alunos apresentarem um bom entendimento das causas do aquecimento global, alguns fatores importantes ainda não eram bem conhecidos.

A partir da exemplificação de algumas conseqüências causadas pelo aumento do efeito estufa (Tabela 5), a resposta "derretimento das calotas polares" atingiu o maior índice (100\%), seguida de "aumento da temperatura média do planeta" $(88,6 \%)$ e "aumento do nível do mar" (71,4\%); outras conseqüências, como "extinção de espécies" e "mudança no padrão de chuvas" tiveram menor incidência $(54,3 \%$ e $40 \%$, respectivamente). Constatou-se que alguns alunos não 
compreendem efetivamente os impactos do aquecimento global, pois $40 \%$ deles responderam que uma das conseqüências do aumento do efeito estufa era a poluição dos rios.

Tabela 5 - Conseqüências do aumento do efeito estufa citadas pelos alunos entrevistados.

\begin{tabular}{cc}
\hline Fatores & \% de indivíduos \\
\hline Aumento do nível do mar & 71,4 \\
Extinção de algumas espécies & 54,3 \\
Derretimento das calotas polares & 100,0 \\
Aumento da temperatura média do & 88,6 \\
planeta & 40,0 \\
Mudança no padrão de chuvas & 40,0 \\
Poluição dos rios &
\end{tabular}

Em relação às alternativas de mitigação dos impactos do efeito estufa, constatou-se uma boa compreensão por parte dos alunos, pois a maioria respondeu como alternativas: diminuir a emissão de $\mathrm{CO}_{2}, \mathrm{CH}_{4}$ e $\mathrm{N}_{2} \mathrm{O}(85,7 \%)$; diminuir o desmatamento (94,3\%); necessidade de reflorestamento $(94,3 \%)$ e incentivo ao uso da bicicleta $(65,7 \%)$. A energia eólica foi pouco escolhida (40\%), possivelmente por exigir que os alunos fizessem uma associação com outros temas como as fontes de energia e seus impactos e, também, por que talvez o termo "eólico" não fosse usual entre eles.

$\mathrm{O}$ que despertou maior preocupação, no entanto, foi à resposta relativa ao "uso de combustíveis fósseis", que foi apontada por $37,1 \%$ dos jovens, podendo justificar-se, novamente, por não ser este um tema comum para os alunos, os quais, inclusive, para não optarem por essa resposta, deveriam recordar que os gases $\mathrm{CO}_{2}, \mathrm{CH}_{4}$ e $\mathrm{N}_{2} \mathrm{O}$ são liberados por ocasião da queima de combustíveis de origem fóssil. Isto não aconteceu com 13 dos alunos participantes da pesquisa.

Constatou-se que $100 \%$ dos alunos desconheciam os termos "mercado de carbono", "seqüestro de carbono" e "mecanismos de desenvolvimento limpo", porém, 40\% já haviam ouvido falar do protocolo de Quioto, indicando que apesar desses alunos estarem bem informados acerca das causas e conseqüências do aquecimento global, existia a necessidade de complementar seus conhecimentos com o uso de conceitos e práticas que já estão presentes no seu cotidiano.

O diagnóstico sobre a assimilação do conhecimento referente aos temas sobre aquecimento global e efeito estufa permitiu encorajar a proposta de construir uma história em quadrinhos, colaborando com um trabalho interdisciplinar, para fortalecimento da aprendizagem quanto a estes dois temas.

A proposta da história em quadrinhos que posteriormente comporá um gibi teve o objetivo de incentivar o aprendizado, a leitura e proporcionar alegria dos alunos. Os alunos que responderam ao questionário aplicado estão no início do aprendizado da escrita e da leitura e, portanto, nada mais adequado que nas salas de aluna, proporcionar o prazer, ludicidade, criatividade e aprendizado.

"O gibi tem linguagem visual, o que é uma ajuda instantânea na evolução do reconhecimento das palavras", diz a pedagoga Thaís Ramos Nucci Zanetti, professora do Colégio Pentágono. Ela explica que, além de ser um material de fácil manipulação, o gibi usa a letra "bastão", que as crianças reconhecem melhor, e traz uma linguagem acessível e cotidiana. "Quando descobrem as histórias em quadrinhos e conseguem compreender a linguagem, encantam-se e avançam na tentativa de leitura", afirma Thaís (http://rpedagogicos.blogspot.com/2008/04/o-uso-degibis-como-recurso-pedaggico.html). 
Na educação infantil, a utilização dos gibis permite desenvolver uma série de atividades, que vão desde a leitura e a interpretação das histórias até a elaboração de diálogos. Diante de um nível menor de dificuldade, o uso do gibi representa um forte estímulo no processo de alfabetização e assimilação de conceitos específicos.

A análise das respostas do questionário aplicado demonstrou que os alunos possuem certo conhecimento a respeito das causas, conseqüências e formas de mitigação dos impactos causados pelo efeito estufa ampliado, porém, apresentam alguns erros conceituais; por exemplo, acreditando que o efeito estufa era um fenômeno ruim, como já citado anteriormente.

Além disso, nunca haviam ouvido falar sobre os termos: mercado de carbono, créditos de carbono e mecanismos de desenvolvimento limpo - mecanismos políticos e comerciais que auxiliam na mitigação dos impactos do aquecimento global. Esses termos podem não estar sendo muito abordados ou difundidos nas instituições de ensino público, no entanto, estão muito presentes na mídia e possivelmente já interferem no cotidiano dos estudantes.

Ressalta-se, aqui, a análise das variações das respostas nos momentos temporais que revelaram o conhecimento pelos alunos no que se refere aos conceitos relativos à Ciência. Destacase também que a aplicação do questionário foi uma metodologia adequada e boa para verificar a viabilidade do uso da história em quadrinho e posteriormente, a confecção de um gibi.

\subsection{História em quadrinhos}

A partir dessas constatações, foi realizada a elaboração e produção de uma HQ para abordar o tema aquecimento global, com o intuito de reparar os erros conceituais diagnosticados, informar sobre os termos desconhecidos e estimular a mudança de hábitos e valores (Figura 6). Atualmente, a capacidade de comunicação da HQ está em evidência, integrando os bancos escolares, sendo usada como material didático auxiliar para diversas atividades, configurando-se como uma estratégia interessante às práticas pedagógicas mais tradicionais. Como produto amplamente difundido na indústria cultural, os quadrinhos influenciam a formação e educação de crianças, de jovens e até de adultos, despertando-lhes a criatividade, sensibilizando-os e provocando-lhes a sociabilidade, o senso crítico e a imaginação, além de influenciar nos costumes e cultura (CATONIO e CRUZ, 2008).

A HQ não foi aplicada a nenhuma turma de alunos, porém, o questionário indicou que estava entre os três meios de leitura preferidos dos alunos, superando até mesmo os livros, que são atualmente os principais recursos didáticos usados no processo ensino-aprendizagem. Esses dados evidenciam o potencial das HQ como instrumento didático-pedagógico para a EA.

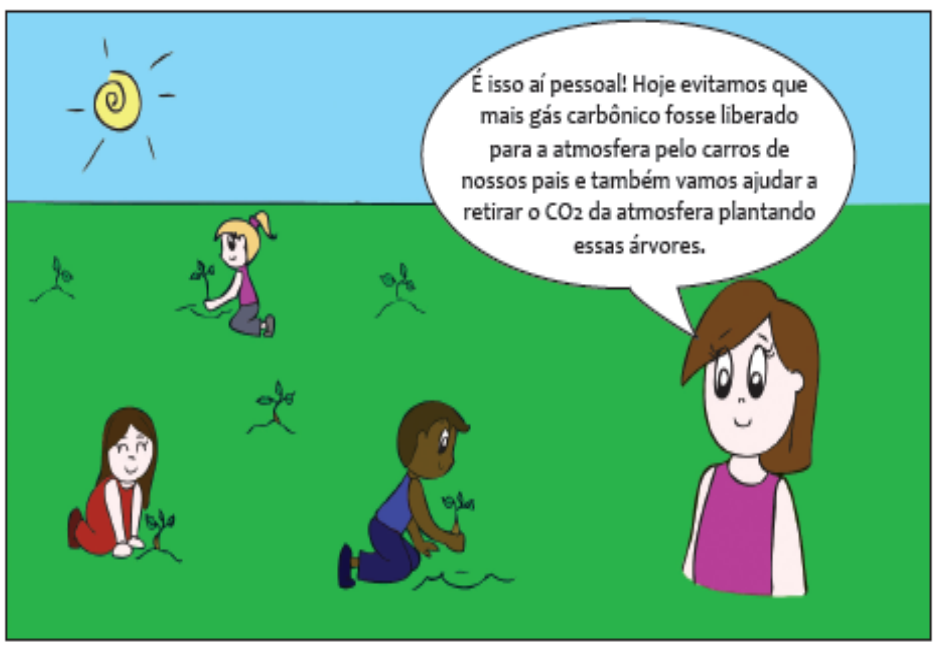

Figura 6. Aninha e Pedrinho convencendo todos os colegas da escola para realizarem ações para diminuir a emissão de $\mathrm{CO}_{2}$ na atmosfera. 


\section{CONSIDERAÇÕES FINAIS}

A pesquisa revelou que muitos alunos possuíam conceitos errôneos e até mesmo ignorância conceitual sobre a temática abordada. Demonstrou também que, além da maioria dos alunos gostarem de ler, a HQ está entre os meios de leitura preferidos por eles, destacando o auxílio que proporciona ao aluno, na medida em que o provoca, de maneira lúdica e prazerosa a desenvolver competências.

A EA pode desenvolver nos indivíduos e na sociedade, de modo geral, valores sociais, conhecimentos e habilidades que podem estimular atitudes que visem à conservação ambiental. Dessa forma, a EA destaca-se como uma proposta didática que pode auxiliar no processo de ensinoaprendizagem dos fenômenos ambientais naturais e na compreensão da relação homem-natureza, seus benefícios e impactos. $O$ entendimento da relação homem-natureza é essencial para a sustentabilidade sócio-ambiental deste planeta, pois compreendendo como essa relação ocorre, os indivíduos podem constatar a importância de conservar o ambiente - elemento vital para a sobrevivência dos seres vivos - pois dele advém às condições abióticas e bióticas ideais necessárias para tal.

Nessa premissa, é importante enfatizar que o uso de histórias em quadrinhos no currículo escolar foi de extrema importância, pois os desenhos e símbolos gráficos exerceram fascínio, expressando profundo significado estético na criação de textos produzidos pelos alunos. Nos resultados alcançados verificou-se que a autonomia de ações no aluno incentiva a capacidade de troca com o outro, errando, acertando e aparando arestas da rotina escolar.

A EA aliada às HQs temáticas poderá se apresentar como um instrumento capaz de propor conceitos e desenvolver atitudes de uma forma prática e dinâmica, conduzindo e orientando o indivíduo a adquirir responsabilidade e consciência sócio-ambiental, rumo à construção de uma sociedade capaz de relacionar-se de forma harmoniosa e sustentável com o ambiente. Esta condição poderá ser essencial para auxiliar nos processos de mitigação dos impactos ambientais causados pelo aquecimento global.

\section{REFERÊNCIAS}

ARAÚJO, M.L.F. A Educação Ambiental, Parâmetros Curriculares e Universidade. Porto Velho: Editora da Universidade Federal de Rondônia, 2002. Disponível em:

$<$ http://www.primeiraversao.unir.br/artigo107.html> Acesso em: 11 out. 2008

BARROS, R.P.; MENDONÇA, R.; SANTOS, D.D.; QUINTAES, G. Determinantes do desempenho educacional no Brasil. Rio de Janeiro: IPEA - Instituto de Pesquisas Econômicas Aplicadas, 2001, 38 p.

BRASIL. Constituição da República Federativa do Brasil. Brasília: Senado, 1988. 168 p.

BRASIL - Secretaria de Educação Fundamental. Parâmetros curriculares nacionais: terceiro e quarto ciclos: apresentação dos temas transversais/Secretaria de Educação Fundamental. Brasília: MEC/SEF, 1998a. 436 p.

BRASIL - Secretaria de Educação Fundamental. Parâmetros curriculares nacionais: terceiro e quarto ciclos do ensino fundamental: introdução aos parâmetros curriculares nacionais / Secretaria de Educação Fundamental. - Brasília: MEC/SEF, 1998b. 174 p. 
BRASIL - RESOLUÇÃO CEB nº . 2, de 7 de abril de 1998. Institui as Diretrizes Curriculares Nacionais para o Ensino Fundamental, 1998c. Disponível em:

http://www.crmariocovas.sp.gov.br/pdf/ccs/pebII/pebII_100-134.pdf>. Acesso em: 22 out. 2008.

BRASIL -. Institui as Diretrizes Curriculares Nacionais para o Ensino Médio, RESOLUÇÃO CEB $\mathrm{n}^{0} .3$, de 26 de junho de 1998d. Disponível em:

http://portalsme.prefeitura.sp.gov.br/documentos/bibliped/31.pdf. Acesso em: 22 out. 2008.

BRASIL - Secretaria de Educação Média e Tecnológica. Parâmetros curriculares nacionais: ensino médio: Ciências da Natureza, Matemática e suas Tecnologias /Secretaria de Educação Média e Tecnológica. Brasília: MEC/SEF, 2000. 58p.

CATONIO, A.C.D.R.; CRUZ, R.O. Gibiteca, biblioteca do gibi. Disponível em: data?<http://www.pr5.ufrj.br/cd_ibero/biblioteca_pdf/educacao/36\%20\%20projetogibitecalb ero.pdf $>$. Acesso em: 05 jul. 2008.

CHANG, M.Y. Seqüestro florestal de carbono no Brasil: Dimensões políticas, socioeconômicas e ecológicas. 1. Ed. São Paulo: Ed. Annablume, 2004. 278 p.

DINIZ, R.C.; OLIVEIRA, S.L.C.; CRUZ, R.F.A.; SIQUEIRA, J.A. As histórias em quadrinhos na aprendizagem. 2006 Disponível em: <http://www.inicepg.univap.br/INIC_. ok.pdf $>$. Acesso em: 10 nov. 2008.

FERRO, J.P. História da banda desenhada infantil portuguesa (das origens até o ABCzinho). Lisboa: Editorial Presença, 1987.

GIESTA, N.C. Histórias em quadrinhos: recursos da Educação Ambiental formal e informal. In: RUSCHEINSKY, A et al. (org.) Educação Ambiental: abordagens múltiplas. Porto Alegre: Artmed, 2002.

IPCC. Climate change 1990. The intergovernmental panel on climate change scientific assessment. Cambridge: Cambridge University Press, United Kingdom, 1990. 416 p.

IPCC. Climate change 2007: the physical science basis. Contribution of working group I to the fourth assessment report of the intergovernmental panel on climate change. Cambridge: Cambridge University Press, United Kingdom, 2007b. 996 p.

LUYTEN, S. O que é história em quadrinhos. São Paulo: Brasiliense, 1985.

PHILIPPI Jr, A.; MALHEIROS, T.F. Saúde ambiental e desenvolvimento. In: PHILIPPI Jr, A; PELICIONI, M. C. F. (ed.). Educação ambiental e Sustentabilidade. Barueri, SP: Manole, 2005. cap. 4, p. 59-83.

REIGOTA, M. Desafios à educação ambiental escolar. In: JACOBI, P. et al. (org.). Educação, ambiente e cidadania: reflexões e experiências. São Paulo: SMA, 1998. p.43-50.

ROCHA, T.N. Histórias em quadrinhos: como informação, divertimento e recurso, 2008. Disponível em: 
$<$ http://taniarochaufba.blogspot.com/2008/06/histriasemquadrinhoscomoinformao.html $>$. Acesso em: 23 jul. 2008.

SÃo PAUlO (Estado). Proposta Curricular do Estado de São Paulo: Ciências/Coord. Maria Inês Fini. São Paulo: SEE, 2008a.

SÃO PAUlO. (Estado). Proposta Curricular do Estado de São Paulo: Biologia/Coord. Maria Inês Fini. São Paulo: SEE, 2008b.

SARRE, A. Carbon Currency - The credits and debits of carbon emission trading. Australin. Academy of Science. Nova: Science in the News. abr. 2000. Disponível em:

$<$ http://www.science.org.au/nova/054/054key.htm>. Acesso em: 13 nov. 2008.

SNYDERS, G. Alunos felizes: reflexão sobre alegria na escola a partir de textos literários. Rio de Janeiro: Paz e Terra, 1996.

UNDP - United Nations Development Programme Report - Beyond Scarcity: Power, poverty and the global water crisis, 2006.

VERGUEIRO, W. Histórias em quadrinhos e serviço de informação: um relacionamento em fase de definição. DataGramaZero - Revista de Ciência da Informação, v.6, n. 2, 2005. Disponível em: $<$ http://diciibicit.Br/archive00000357>. Acesso em: 12 nov. 2008. 